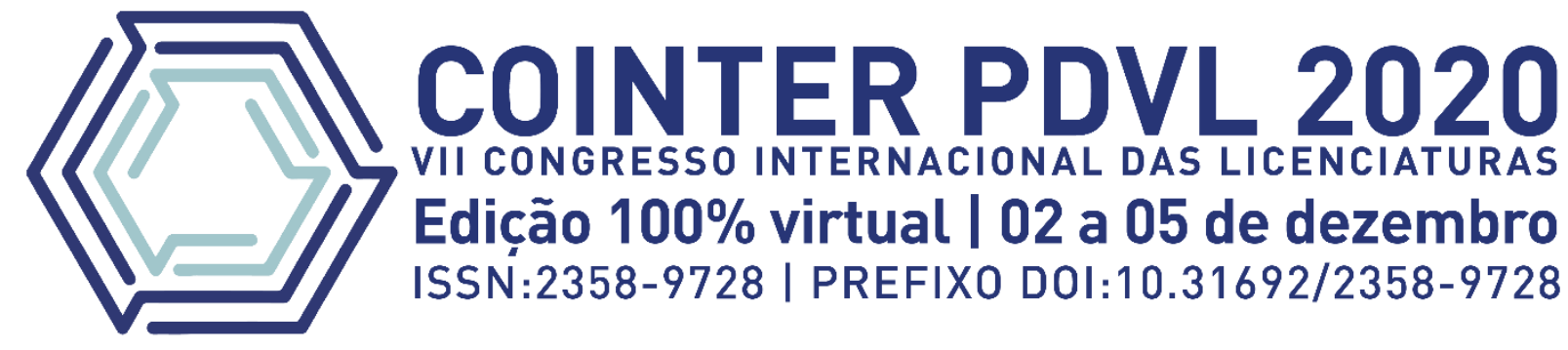

\title{
AS CONTRIBUIÇÕES DAS ATIVIDADES EXPERIMENTAIS NO ENSINO DE QUÍMICA.
}

\section{LAS CONTRIBUCIONES DE LAS ACTIVIDADES EXPERIMENTALES EN LA ENSEÑANZA DE LA QUÍMICA. \\ THE CONTRIBUTIONS OF EXPERIMENTAL ACTIVITIES IN THE} TEACHING OF CHEMISTRY.

\author{
Apresentação: Comunicação Oral \\ Maria Grasielly da Silva Nascimento ${ }^{1}$; Áurea Vitória Pereira de Aguiar²; Jaqueline Souza de Barros ${ }^{3}$ Fernando $^{2}$ \\ Cleyton Henrique de Mendonça Silva ${ }^{4}$; Kilma da Silva Lima Viana ${ }^{5}$
}

DOI: https://doi.org/10.31692/2358-9728.VIICOINTERPDVL.0393

\section{RESUMO}

O ensino de Química tem mantidos práticas que estão relacionadas às abordagens mais tradicionais, baseadas em aulas expositivas, descontextualizadas, retirando, assim, da química a sua natureza que é, essencialmente, experimental. A consequência disso é a formação de estudantes que não despertam o interesse para essa área de conhecimento. Inquieta-nos saber: quais as principais características das práticas experimentais no ensino de Química? Para responder a essa inquietação, essa pesquisa teve o objetivo de identificar as principais abordagens experimentais no ensino de Química. O campo de pesquisa foram duas escolas da Rede Pública do Estado de Pernambuco e os participantes da pesquisa foram 32 estudantes do Ensino Médio dessas escolas. Foram realizados questionários com os estudantes com pergunta aberta e fechadas, e entrevistas com 2 professores. Foi observado que as práticas experimentais

\footnotetext{
${ }^{1}$ Graduanda do Curso de Química do Instituto Federal de Pernambuco - IFPE - Campus Vitória de Santo Antão, mariagrasielly2019@gmail.com;

${ }^{2}$ Graduanda do Curso de Química do Instituto Federal de Pernambuco - IFPE - Campus Vitória de Santo Antão, avpas@discente.ifpe.edu.br

${ }^{3}$ Graduanda do Curso de Química do Instituto Federal de Pernambuco - IFPE - Campus Vitória de Santo Antão, Jaquelinesb2019@gmail.com

${ }^{4}$ Mestre do Curso de Pós-Graduação em Educação em Ciências e Matemática - PPGECM - da Universidade Federal de Pernambuco - UFPE - Centro Acadêmico do Agreste - CAA, fernando.cleyton@institutoidv.org

${ }_{5}^{5}$ Doutora em Ensino de Ciências (Física e Química), Professora do IFPE, Presidente do IIDV, Coordenadora Geral do PDVL, Líder do GEPEC, kilma.viana@institutoidv.org
} 
no Ensino de química, na escola de rede pública, nem sempre prioriza as aulas práticas, muitas vezes por conta do espaço e também dos materiais. O objetivo das práticas experimentais é auxiliar os estudantes no processo de ensino-aprendizagem, e também ajudar os estudantes na aprendizagem dos conteúdos de química, de acordo com as respostas dos estudantes, observamos que eles acham muito importante essa prática, e 44,15\% dos alunos responderam que o professor não realiza essa prática, a utilização das práticas experimentais é muito importante para a aprendizagem dos alunos, mais nem sempre o espaço favorece. Observamos também, através de uma pesquisa bibliográfica, que existem diversas possibilidades do professor realizar essas atividades experimentais em sala de aula. Além disso, verificamos também o quanto o ensino de Química precisa ser renovado, afinal, esses estudos trazem perspectivas que não são corriqueiras nas salas de aula. Muitos professores permanecem com práticas experimentais relacionadas às abordagens tradicionais. Assim, ressaltamos a importâncias dessas propostas serem discutidas nos cursos de formação de professores para que o ensino, no nosso caso, da Química supere as práticas tradicionais que, historicamente são realizadas.

Palavras-chaves: Práticas Experimentais,Ensino de Química,Ensino Médio.

\section{RESUMEN}

La enseñanza de la Química ha mantenido prácticas que se relacionan con enfoques más tradicionales, basados en clases expositivas, descontextualizadas, sacando así, de la química, su naturaleza, que es, esencialmente, experimental. La consecuencia de esto es la formación de estudiantes que no despiertan interés en esta área del conocimiento. Nos preocupa saber: ¿Cuáles son las principales características de las prácticas experimentales en la enseñanza de la Química? Para responder a esta inquietud, esta investigación tuvo como objetivo identificar los principales enfoques experimentales en la enseñanza de la Química. El campo de investigación fueron dos escuelas públicas en el estado de Pernambuco y los participantes de la investigación fueron 32 estudiantes de secundaria de estas escuelas. Se realizaron cuestionarios con estudiantes con preguntas abiertas y cerradas y entrevistas con 2 profesores. Se observó que las prácticas experimentales en la enseñanza de la química, en las escuelas públicas, no siempre priorizan las clases prácticas, muchas veces por espacio y materiales. El objetivo de las prácticas experimentales es asistir a los estudiantes en el proceso de enseñanza-aprendizaje, y también ayudar a los estudiantes en el aprendizaje de los contenidos de la química, de acuerdo con las respuestas de los estudiantes, observamos que encuentran muy importante esta práctica, y $44.15 \%$ de los estudiantes respondió que el docente no realiza esta práctica, el uso de prácticas 
experimentales es muy importante para el aprendizaje de los estudiantes, pero el espacio no siempre es favorable. También observamos, mediante una búsqueda bibliográfica, que existen varias posibilidades para que el docente lleve a cabo estas actividades experimentales en el aula. Además, también comprobamos cuánto hay que renovar la enseñanza de la Química, al fin y al cabo, estos estudios aportan perspectivas que no son comunes en las aulas. Muchos profesores permanecen con prácticas experimentales relacionadas con enfoques tradicionales. Así, destacamos la importancia de que estas propuestas sean discutidas en los cursos de formación docente para que la enseñanza, en nuestro caso, de la Química supere las prácticas tradicionales que, históricamente, se llevan a cabo.

Palabras clave: Prácticas experimentales, Enseñanza de la química, Bachillerato.

\section{ABSTRACT}

The teaching of Chemistry has maintained practices that are related to the most traditional approaches, based on expository classes, decontextualized, thus removing, from chemistry, its nature, which is, essentially, experimental. The consequence of this is the training of students who do not arouse interest in this area of knowledge. It worries us to know: what are the main characteristics of experimental practices in the teaching of Chemistry? To answer this concern, this research aimed to identify the main experimental approaches in the teaching of Chemistry. The research field were two public schools in the State of Pernambuco and the research participants were 32 high school students from these schools. Questionnaires were conducted with students with open and closed questions, and interviews with 2 teachers. It was observed that experimental practices in teaching chemistry, in public schools, do not always prioritize practical classes, often due to space and materials. The objective of experimental practices is to assist students in the teaching-learning process, and also to assist students in learning the contents of chemistry, according to the students' responses, we observe that they find this practice very important, and $44.15 \%$ of the students replied that the teacher does not perform this practice, the use of experimental practices is very important for students' learning, but space is not always favorable. We also observed, through a bibliographic search, that there are several possibilities for the teacher to carry out these experimental activities in the classroom. In addition, we also verified how much the teaching of Chemistry needs to be renewed, after all, these studies bring perspectives that are not common in the classrooms. Many teachers remain with experimental practices related to traditional approaches. Thus, we emphasize the importance of these proposals being discussed in teacher training courses so that the teaching, in our case, of Chemistry surpasses the traditional practices that, historically, are 
carried out.

Keywords: Experimental Practices, Chemistry Teaching, High School.

\section{INTRODUÇÃO}

É necessário formar o professor que compreenda a amplitude, dificuldade e abrangência dos conteúdos a serem ensinados, por outro, deseja-se que o mesmo seja capaz de elaborar procedimentos metodológicos coerentes com o objeto de ensino específico.

Ressalta-se ainda a necessidade de o professor articular a teoria e a prática, superando a dicotomia tão presente nas salas de aula, pois, havendo um programa de aulas experimentais no ensino da Química, de nada adiantará se esta não estiver diretamente relacionada e concomitante com as aulas teóricas e os conceitos abordados na sala de aula.

Na etapa do Ensino Médio, as Diretrizes Curriculares Nacionais para Educação Básica (DCNEB) (BRASIL, 2013) sinalizam que um dos desafios é o desenvolvimento científico e tecnológico, que podem ser tratados por meio de metodologias de ensino que expressem significados para os estudantes. Assim, a escola passa a ter como objetivo um ensino que preze pela formação de sujeitos críticos e reflexivos com o ambiente que os rodeiam, construindo uma educação para a formação cidadã. Uma educação que não só contemple os conteúdos das diversas disciplinas escolares, mas também consiga abordar os problemas da sociedade, e que leve os estudantes a construírem a sua identidade e pertencimento social.

No contexto do Ensino de Química, os Parâmetros Curriculares Nacionais do Ensino Médio: Orientações Educacionais Complementares aos Parâmetros Curriculares Nacionais (PCN+) (BRASIL, 2002), acrescentam que o Ensino de Química pode romper com os antigos processos de ensino balizados, principalmente, na visualização de informações, e, desse modo, buscar atenuar a visão fragmentada que não leva em consideração o cotidiano e vivência dos alunos.

A forma como a aprendizagem é avaliada é de fundamental importância para se ter uma resposta plausível sobre a consolidação do processo de ensino-aprendizagem. Proporcionando, dessa maneira, a formação de estudantes críticos, reflexivos e socialmente responsáveis, mantendo-se na inércia da reprodução. No entanto, cada vez mais a sociedade exige estudantes que se posicionem, julguem e tomem decisões, e que sejam responsabilizados por isso. (BRASIL, 2006).

O ensino de Química tem mantidos práticas que estão relacionadas às abordagens mais tradicionais (MIZUKAMI, 1986), baseadas em aulas expositivas, descontextualizadas, retirando, assim, da química a sua natureza que é, essencialmente, experimental. A 
consequência disso é a formação de estudantes que não despertam o interesse para essa área de conhecimento. Diante disso, justificamos a necessidade de focarmos a pesquisa acerca das práticas experimentais nas aulas de Química, pois inquieta-nos saber: quais as principais características das práticas experimentais no ensino de Química? Para responder a essa inquietação, essa pesquisa teve o objetivo de identificar as principais abordagens experimentais no ensino de Química. Para isso, foi realizada uma pesquisa bibliográfica, tendo como foco os estudos de (Alves Filho 2000) e (Carvalho 2013).

\section{FUNDAMENTAÇÃO TEÓRICA}

Ao passar dos séculos a Educação vai se moldando nas perspectivas econômicas, sociais e tecnológicas. Dessa forma, o ensino foi buscando formar não apenas cientistas, escritores, inventores, mas cidadãos, os quais possam pensar, refletir e agir perante o contexto ao qual está inserido. No ensino de Ciências, em especial no ensino da Química, essa nova perspectiva de ensino se adequa perfeitamente, pelo fato da Química ser uma ciência natural e experimental.

A própria essência da Química revela a importância de introduzir este tipo de atividade ao aluno, esta ciência se relaciona com a natureza, sendo assim os experimentos propiciam ao estudante uma compreensão mais científica das transformações que nela ocorrem (AMARAL, 1996).

O objetivo da Química compreende a natureza, e os experimentos propiciam ao aluno uma compreensão mais científica das transformações que nela ocorrem. Saber punhados de nomes e de fórmulas, decorar reações e propriedades, sem conseguir relacioná-los cientificamente com a natureza, não é conhecer Química. Essa não é uma ciência petrificada; seus conceitos, leis e teorias não foram estabelecidos, mas têm a sua dinâmica própria (SAVIANI, 2000).

Nesse sentido, a utilização de atividades práticas nas aulas de Química, segundo Alves Filho (2000) possui o objetivo pedagógico de aperfeiçoar o processo de ensino aprendizagem tornando-o interativo e não um processo unilateral, no qual os alunos possam participar de forma ativa. Desse modo, o aluno como protagonista do seu aprendizado poderá construir um conhecimento de significados para sua formação tanto para sua vida pessoal, quanto para seu convívio em sociedade. Por conseguinte, essas novas formas de ensinar e aprender implicam em um novo olhar para os estudantes, para o que é ensino e o que é a aprendizagem, oportunizando momentos de analise, reflexão e compreensão das vivências nas salas de aula.

Ao longo do tempo, a Química, que é uma ciência dinâmica, vem perdendo sua essência. Sua prática tem sido relacionada à abordagem tradicional, com ênfase nos aspectos teóricos, 
distanciando-se da sua natureza empírica e experimental e contextualizada, fundamental para a aprendizagem de conceitos na área (LIMA, 2008).

Por outro lado, diversas pesquisas apontam para o desinteresse de estudantes para se tornarem professores, principalmente na área de química. Os motivos são diversos para a aversão pela área, entre eles, a ausência de práticas motivadoras. Dessa forma, mesmo considerando a carreira do professor de grande importância, os jovens não têm optado por ela (VIANA, 2014).

\section{METODOLOGIA}

Esta pesquisa apresenta uma abordagem qualitativa e se apresente enquanto uma pesquisa de campo. Os campos de pesquisas foram as escolas da Rede Pública Estadual e os participantes da pesquisa foram os professores que ministram aulas de química no Ensino Médio dessas escolas e seus estudantes. Diante do exposto, os instrumentos utilizados foram uma revisão bibliográfica acerca das atividades experimentais a partir de Alves Filho (2000), e também a partir do livro de Anna Maria Pessoa de Carvalho (2013), entrevistas semiestruturadas com os professores e questionários com os estudantes.

Com relação aos procedimentos da pesquisa, inicialmente, identificamos as concepções dos professores, que ministram aulas de química no Ensino Médio sobre práticas experimentais. Em seguida, identificamos as aproximações e distanciamentos entre as concepções dos professores e as novas perspectivas de ensino. Posteriormente, identificamos as percepções dos estudantes acerca da aprendizagem de conceitos em química. Por fim, analisamos as contribuições das práticas experimentais para a aprendizagem de conceitos em Química na visão dos professores e estudantes.

\section{RESULTADOS E DISCUSSÃO}

Inicialmente foi realizada uma pesquisa bibliográfica acerca das atividades experimentais a partir de (Alves Filho 2000), e também a partir do livro de Anna Maria Pessoa de (Carvalho 2013), intitulado ensino de ciências por investigação: condições para implementação em sala de aula.

Baseando-se nos estudos realizados por (Carvalho 2013), observa-se que o material didático, usado na aula de experimental, tem que ser bem organizado para com que o aluno consiga resolve-lo com facilidade, e esse material tem o intuito de despertar a atenção deles para que possam chegar a uma solução, querendo sempre resolver mais, sem se esgotar. E essas questões tem que ser muito bem elaboradas e com características apontadas pelos referencias 
teóricos, estando associado na cultura social dos alunos.

As interações didáticas entre estudante-estudante e professor-estudante são tão importantes como o planejamento do material didático e a elaboração do problema. (Carvalho 2013), esse processo se divide em etapas:

$\checkmark$ Etapa de distribuição do material experimental e proposição do problema pelo professor;

$\checkmark$ Etapa de resolução de problema pelos alunos;

$\checkmark$ Etapa da sistematização dos conhecimentos elaborados nos grupos;

$\checkmark$ Etapa de escrever e desenhar.

\section{Na etapa de distribuição do material experimental e proposição do problema pelo}

professor, o professor vai dividir a sala em pequenos grupos, distribui o material, o professor apresenta o problema aos alunos e pergunta se eles entenderam o problema que eles vão resolver, e que o professor tenha cuidado para que ele sem querer indique a resposta, pois acaba a possibilidade do aluno a pensar sobre o problema.

Na etapa de resolução de problema pelos alunos é importante as ações manipulativas que vão dar condições para que os alunos pensem e tenham ideias para resolver, e essas resoluções de problemas acontecem em pequenos grupos, pois também tem aquela parte de afetividade que é mais fácil propor seus pensamentos e ideias com o seu colega do que o seu professor, e também os alunos tem que errar pois através de seus erros eles vão pensar onde eles erraram e tentar verificar o que aconteceu de errado tudo isso é mais fácil sem o professor por perto, pois nesta etapa o professor deve examinar se os grupos entenderam o problema, e deixar com que os alunos tentem resolver eles sozinhos.

Na etapa de sistematização dos conhecimentos elaborados em grupos, o professor vai observar se os alunos já terminaram de responder e se sim recolher todo o material de experimentação, e organizar a turma para debater sobre as questões se possível a turma toda em um circulo para que os alunos possam melhor debater, e por meios de perguntas os alunos vão se interagindo um com outro e compartilhando conhecimentos e fazendo levantamento de dados e também construção de evidencias, e junto a sala vai fazendo uma argumentação cientifica.

Na etapa de escrever e desenhar, esta é uma etapa individual de conhecimentos, pois o professor neste momento vai pedir para que cada aluno escreva e desenhe o que aprenderam na sala de aula.

Carvalho (2013) afirma que o ensino investigativo deve ter uma sequência, e na maioria 
das vezes se inicia por um problema, experimental ou teórico, contextualizado para que desperte no aluno através desses pontos, curiosidades, para que sempre eles busquem mas pelo assunto, e sempre levar textos relacionados a esses pontos para sala de aula, para que os alunos tirem suas dúvidas e venham a discutir sobre o conteúdo, e essas atividades podem levar os alunos cada vez mais a se aprofundar no conteúdo, levando-os a saberem mais sobre o assunto. E o professor precisa de mais autocontrole na etapa de resolução do problema, e antes, depois e durante de começar a fazer as manipulações dos aparelhos o professor deve fazer perguntas aos alunos para que eles pensem e argumentem sobre o que está acontecendo naquele ambiente, para que eles encontrem soluções e também que ele reflita de dados importantes sobre o experimento proposto, e que também eles intendam o conceito e objetivo dos problemas. E que também que os alunos mostrem o que aprenderam por meios de trabalhos individuais.

Tomando como base Alves Filho (2000), observamos que ele classifica as atividades experimentais da seguinte forma: elas a atividade experimental histórica; atividade experimental de compartilhamento; atividade experimental modelizadora; atividade experimental conflitiva; atividade experimental crítica; atividade experimental de comprovação e atividade experimental de comprovação.

$\mathrm{Na}$ atividade experimental histórica fala sobre a forma de reconstruir um cenário histórico determinado através de uma atividade experimental, fazendo com que o professor valorize o contexto histórico permitindo ao professor trabalhar de uma maneira mais versátil. E a história da ciência deve encaminhar um cenário próprio, pois se for ao contrário não tem sido o fenômeno didático.

A atividade experimental de compartilhamento é um meio de comunicação quem possibilita uma comunicação simples, e interpretações dentro de um mesmo quadro teórico. E essas atividades de compartilhamento seriam relações de causa e também de efeito que pode ser interpretada como a localização de variáveis e o batismo das grandezas físicas.

A atividade experimental modelizadora pode funcionar como uma conjunção onde os alunos vão ser modelizadores, pois eles vão intender a utilidade relativa dos modelos. Os alunos vão fazer modelização através de atividades experimentais que terá que considerar o procedimento restrito, e nele devem ser encontrados presentes o modelo teórico e o modelo empírico.

A atividade experimental conflitiva proporciona ao professor a permitir algumas concepções não formais dos estudantes, tendo visibilidade o diálogo construtivo dos estudantes. E as atividades experimentais devem eliminar as diferenças e que possam permitir que os estudantes possam chegar as suas próprias concepções. 
A atividade experimental crítica tem de grande importância no dialogo construtivista, e as ideias previas também se mostram presente nessas atividades só que de uma forma diferente.

A atividade experimental comprovação tem como objetivo comprar leis físicas, verificar previsões teóricas e exercitar o método experimental, e essa atividade experimental funciona de uma forma tradicional, mas de um método mais rico, pois vai ter que utilizar procedimentos e métodos experimental, e também o aluno pode explorar e enfatizar o método experimental com um instrumento investigativo.

As atividades experimentais de simulação atualmente são voltadas mais para o lado da tecnologia, e é necessário que os alunos tenham contato com matérias reais para que possam fazer relação entre a teoria e a prática, e também desenvolver e compreender a realidade da ciência, e que tenham careza quando forem realizar suas pesquisas.

\section{Resultados da Entrevista com os Professores}

Inicialmente foram feitas as entrevistas com os professores de escolas públicas, que atuam na escola Erem Tristão Ferreira Bessa, e na Escola Cônego Fernando Passos, e foram utilizadas as mesmas perguntas para os professores.

Pergunta 1. O Senhor(a) realiza atividades experimentais na escola que você atua?

Com que frequência?

Pergunta 2. Como o senhor(a) seleciona os conteúdos que vão ser trabalhados a partir de atividades experimentais, e os conteúdos que não são?

Pergunta 3. A escola que o senhor(a) atua tem laboratório de Química? ou o senhor realiza os experimentos na sala de aula com matérias alternativos?

Pergunta 4. Como é sua prática na sala de aula, você utiliza mais aula expositiva, ou com os estudantes sem grupos, nas suas aulas os alunos são mais ativos ou passivos? Descreva.

Pergunta 5. Como é que senhor(a) acha que ministra as aulas na disciplina de química? Sobre como devem ocorrer as aulas de química

Pergunta 6. Como hoje em dia estamos em aulas online, as suas aulas práticas acontecem do mesmo jeito? Você utiliza algum software, como simulador para os experimentos? Ou permanecem sem aulas experimentais?

Pergunta 7. Qual a importância para o senhor(a) em relação das práticas experimentais na aprendizagem do conceito de Química? 
R1. Professor: Realizo dentro do possível, Por que a escola não oferece muitos recursos tanto estruturais quanto matérias para isso, mais sempre que for possível estou utilizando.

R2. Professor: A escolhas das aulas e dos conteúdos se vai ser utilizado a experimentação ou não vai mas de acordar com o experimento, Assim primeiro eu observo quais são os experimentos possíveis que cabem naquele conteúdo e vejo se é possível realizá-los, assim se eu vou ter condições de realizar eles Caso eu tenha condições de realizar eu realizo, Caso não tenha condições eu vou apenas para aula teórica ou utilizo outras metodologias como os jogos didáticos como já usei várias vezes.

R3. Professor: A escola ela tem laboratório mas o laboratório da escola foi algo que foi algo que foi construído para suprir a falta de um laboratório, e ele não foi construído de acordo com às necessidades físicas que um laboratório precisa ter, ele é muito pequeno, muito pequeno mesmo e não cabe 15 alunos dentro dele pra poder ter toda segurança necessária que nós sabemos que tem que ter, então eu já levei para o laboratório as turmas divididas mas é mais comum eu utilizar a experimentação em sala de aulas e com matérias de baixo custo mas também utilizando as vidrarias e alguns reagentes que tem lá que se encontram lá no laboratório, por que as vidrarias mas usáveis as vidrarias mas comuns lá tem, os reagentes também alguns tem mais de fácil acesso também tem mas não são todos né, então aí sempre em um experimento vai faltar um ou outro reagentes aí podemos substituir por alguns matérias de baixo custo, mais sempre assim eu tento não utilizar sempre matérias de baixo custo eu gosto sempre de misturar com matérias do laboratório.

R4. Professor: eu costumo utilizar mas as aulas expositivas justamente por essa falta de estrutura que eu citei anteriormente, e infelizmente os alunos eles tem uma postura mas passiva assim se for falar no geral, claro que tem um ou outro que participa, interagem que é mais ativo durante as aulas, mas é mais comum que eles sejam passivos, eles mais ouvem e em caso eles tenham alguma dúvida, no final eles perguntam ou comentam alguma coisa, mais são poucos que comentam.

R5. Professor: A partir do que a gente está vivendo agora e como a escola é pública é muito difícil trabalhar com os estudantes, por que normalmente a gente preferi fazer as gravações das aulas e mandar pra eles, do que fazer as aulas ao vivo naquele momento através do Google meet ou zoom, ou alguma plataforma desse estilo, por que nem todos os estudantes tem acesso a internet, ou um celular ou um computador ou um tablet, eles não tem, claro que uma grande maioria tem celular, mais ainda mesmo assim não tem uma internet que seja capaz de participar de uma aula ao vivo, então a gente normalmente costuma gravar as aulas e mandar pra eles, a parte experimental como eu disse a você como eu estou no terceiro ano só foi possível com um 
conteúdo de eletroquímica, e agente fez sim um experimento só que aí eu expliquei o conteúdo a eles e mandei um vídeo do experimento de pilha de limão, pilha de batata, e pedi pra que eles replicassem o experimento, não foi nada assim muito investigativo, foi mais de verificação mesmo, por que eles já sabia o que ia acontecer mas fizeram mesmo assim, esperando obter o mesmo resultado, mais daí deu pra ter algumas discursões por que, alguns alunos usando os mesmo matérias não deu certo e agente foi em busca dos motivos, por que não deu certo aí consegui fazer várias discussões em cima disso, por exemplo do limão e que era menor com isso não gerava tanta carga, tanto íons, então a gente conseguiu fazer essas discursões, mais é muito complicado agente dar aula ao vivo, pra você ter ideia nós temos 4 turmas com cercas de 40 alunos, e isso dar mais ou menos umas 160 pessoas contando as quatros turmas, então normalmente a gente junta todos os alunos para dar uma aula, pra não ter que dar uma aula por turma e como toda turma está vendo o mesmo conteúdo aí nós junta todas a turmas do terceiro ano pra dar aula e agente fez um esse teste né e convidou todos os alunos e marcamos a aula tudo certinho, é dessas 160 pessoas só 8 pessoas participaram da aula, então isso frustra demais a gente né, acaba desanimando bastante, então é muito mais fácil e eles participam muito mais quando a gente faz as gravações das aulas e manda pra eles, do que quando a gente tem essa aula ao vivo.

R6. Professor: Isso se dar essa diferença de participação se dar justamente por que naquele momento ele pode não ter acesso à internet, e participar da aula mais em algum momento do dia ou da semana ele pode ir pra casa da tia, do avô, da avó, ele pega o celular da mãe, da irmã, e consegue assistir da a aula que a gente gravou e deixou disponível pra eles então é bem melhor para os alunos assistirem as aulas gravadas do que a gente ter aquela aula naquele momento ao vivo.

R7. Professor: A gente que é professor de química né que está estudando e pesquisando a gente é muito comum ler em artigo que a química é uma ciência experimental e por isso deve estar presente a experimentação em seu processo de ensino aprendizagem, e mesmo sendo uma coisa tão falada tão falada, mais faz todo sentido, faz toda razão, se aquilo que a gente ensina, aquela teoria ela é vivenciado no cotidiano dos alunos em algum momento por eles ou a gente pode fazer com que ele vivencie por que não fazer? se isso vai facilitar a aprendizagem do aluno e vai dar um motivo para aquela resposta, vai dar uma resposta para aquela pergunta muito comum que eles fazem, pra que estudar isso? então quando a gente traz a experimentação e consegue relacionar aquele experimento com cotidiano dele que aquilo acontece ao seu redor e muitas vezes ele não presta atenção, a gente dá um Significado para aquela aprendizagem dele 
e quando a gente significa a aprendizagem ela se dá de maneira muito mais sólida e muito mais eficaz do que quando a gente apenas traz o conceitos com que os alunos vai apenas decorar, para pôr em prática na prova e depois vai esquecer é muito melhor a gente trazer essa aprendizagem dessa forma através da experimentação do que apenas dessa forma teórica, eu acho que é isso a importância da experimentação nas aulas de química.

R1. Professora: No momento nós não estamos fazendo experimentos, fazendo muitas atividades práticas por conta da distância, nesse período de pandemia, quando eu estava na escola, no ensino presencial, a gente sempre fazia ou alguma prática mesmo que simples em sala de aula ou em laboratório, nós não temos muitos produtos disponíveis, aí eu sempre combinei com os estudantes para que eles levassem em grupos para facilitar, agora durante a pandemia, eu só realizei uma atividade prática com os $3^{\circ}$ anos que foi com relação a reciclagem de alguns materiais, trabalhando os conteúdos matérias plásticos, PVC, aí quando a gente estava trabalhando os polímeros naturais e sintéticos, eles perceberão também, que estavam presentes em alguns materiais que nós utilizamos nosso dia a dia, aí com esse matérias eles produziram, realizaram a reciclagem, produziram, confeccionaram novos produtos.

R2. Professora: Na rede estadual nós seguimos o currículo, o currículo do Estado e agora na pandemia houve uma adaptação, por que ele é bastante extenso e devido ao período que estamos vivenciando, como os estudantes não estão tendo tanta facilidade, nem tem como tirar dúvidas lá, como nas aulas presencias, o currículo foi reorganizado, aí a gente segue sempre o que é repassado e orientando pela regional. Existe alguns conteúdos que a gente tem mais facilidade né de realizar uma prática mas aí a eu sempre vejo se tem alguma possibilidade, se não uma prática usando alguns materiais, podem também utilizar jogos porque aí parte dos jogos também a aula se tornar mais dinâmica aí alguns alunos conseguem absorver o conteúdo mais facilmente dessa forma, inclusive alguns jogos que que utilizo e já utilizei foram propostos por estagiários, inclusive Grasielly que está me entrevistando, e outros estagiários que levaram maneiras práticas de vivenciar os conteúdos.

R3. Professora: Na escola com o cônego tem o laboratório de informática, de ciências que é utilizado para biologia, ciências, química e física, e tem um laboratório de matemática, no início quando ele foi construído lá na escola trouxeram os materiais, tinha até uma variedade inclusive de substâncias aí com tempo foi sendo utilizado, alguns materiais se venceram aí foram encaminhado para o descarte correto, e aí geralmente os estudantes eles trazem, a gente formam grupos e trazem os materiais necessários 
R4. Professora: Com relação as aulas como eu já coloquei, tem as aulas expositivas onde pode se usar o data show, alguns aparelhos que tem no laboratório, que eu trago pra sala de aula pra demonstrar. por exemplo quando a gente fala do conteúdo sobre os átomos, $\mathrm{n}$ tem alguns modelos átomos que foram confeccionados, que ficaram lá no laboratório de ciências, e aí geralmente quando tem algo que chama atenção a prática, grande parte participar, mais varia muito pela turma, tem turmas que são bem mais participativas e outras não, alguns estudantes são mais retraídos, ou desinteressados, mais aí varia muito de acordo com a turma.

R5. Professora: Eu sempre comento que existem algumas dificuldades né, desde o data show, o projetor, porque aí o professor ele tem que montar, aí acaba perdendo um pouco do tempo da aula, a questão de algumas turmas serem mais barulhentas, aí a gente tem que no início controlar, acalmar os ânimos pra poder iniciar o conteúdo, aí tudo isso o estudante que realmente se interessa acaba perdendo tempo, aguardando o professor organizar tudo isso, com relação as aulas eu acredito que o professor ele sempre deve tentar mudar por que o estudante de hoje não quer simplesmente chegar lá e escutar o conteúdo, antigamente a maioria dava por satisfeito né, hoje em dia não muitos querem novidades, ai por isso a importância de sempre trazer um vídeo diferenciado, mostrando algumas reações que vai chamar atenção, tentar introduzir a aula e alguns conteúdos de maneira diferente de uma maneira mais Lúdica.

R6. Professora: Agora nesse período de pandemia como eu falei eu tive dificuldade de realizar as atividades práticas, com relação aos $3^{\circ}$ anos eu consegui fazer uma, para que eles produzissem com os materiais nas próprias casas e enviassem os vídeos, fotos do que eles produziram, mas aí eu não utilizei nenhum aplicativo ainda que eles pudessem realizar não, o estado ele está criando novas plataformas, o classom Rum é uma, que vai possibilitar que os professores possam colocar alguns vídeos, que o professor faça algumas atividades diferenciadas; aí isso vai facilitar agora.

R7. Professora: Eu sempre digo para que o aluno ele compreenda o conteúdo é necessário que ele veja que aquilo está presente no dia a dia, onde ocorre, como ocorre por isso as atividades experimentais elas facilitam na aprendizagem, e aí quando a gente vai introduzir o estudo da química é importante que a gente mostra no dia a dia tudo o que é constituído pelas partículas atômicas, tudo o que a química estuda, todas as transformações, e aí o aluno vai percebendo o quanto é importante a gente conhecer todas as reações que acontecem constantemente para facilitar para que ele possa também ter o conhecimento dos componentes de alguns medicamentos de alguns materiais que nos utilizam no dia a dia, se pode ser tóxico, se pode ser seguro utilizar como a própria naftalina quando anda sua Constituição então a importância dos 
experimentos sempre vai estar vinculada com essa questão da aprendizagem mais solidificada pois por que cada estudante se aprende no seu tempo e aprende da sua maneira, mas a partir de jogos, de experimentos, de maneiras diferenciadas do professor demonstrar o conteúdo faz com que o professor consiga atingir a maioria dos estudantes e é isso a gente busca né, sempre atingir o maior público possível.

Observamos que de acordo com as respostas dos professores, notamos que eles não utilizam com frequência a utilização das práticas experimentais em sala de aula, muitas vezes por conta do tempo que é curto, e percebemos também que nas escolas os professores sentem falta de materias, reagentes para fazer essa prática, mais mesmo com as dificuldads que os professores enfrentam no dia a dia, eles sempre buscam meios e formas diferentes para que venha acontecer essa prática, pois eles sabem o quanto é importante para a aprendizagem dos seus alunos, e quando os professores utilizam as práticas experimentais eles sempre buscam relacionar com o cotidiano, com a natureza, e que os alunos percebam que a química está presente no dia dia deles, fazendo com que eles compreendam mais o conteúdo e que eles venham dar mais significado para aquela aprendizagem, e de acordo com (SAVIANI, 2000) se os alunos não conseguirem relacionar o conteúdo com natureza, coom o seu cotidiano eles não aprenderam química, eles não tem conhecimento sobre a química, pois não significa nada se os alunos souberem fórmulas, decorar reações e propriedades, e não conseguir relaciona-las, e é isso que nós percebos através das entrevistas com os professores que eles buscam isso, que os alunos tenham esse conhecimento sobre a química, não que eles apenas decorem fórmulas e venham tirar boas notas nas provas, mais que eles aprendam e que venham utilizar e relacionar elas com o seu cotidiano, e através das práticas experimentais elas proporcionam aos alunos uma maior compreensão das transformações da química.

\section{Resultados dos Questionários dos Estudantes:}

O questionário contém em torno de 5 questões, que foi aplicado através do google forms, para os alunos do $3^{\circ}$ ano do ensino médio da escola Erem Tristão Ferreira Bessa, onde ao todo foram 12 alunos que responderam. E o questionário foi aplicado também para os alunos do $2^{\circ}$ ano da escola Cônego Fernando Passos, que ao todo foram 20 alunos que responderam.

Pergunta1. Para você qual a importância das práticas experimentais para aprender os conceitos de química?

Pergunta2.Você tem dificuldade para aprender química?

Pergunta3. Você tem aulas experimentais na aula de Química? 
Pergunta4. Sua escola tem laboratório de química?

Pergunta5.Você gosta da matéria de Química?

Iremos iniciar com a resposta da escola Erem Tristão Ferreira Bessa.

\section{Resposta1.}

Aluno1. Ajuda a esclarecer o assunto desde que é muito difícil entender algo que muitas vezes os alunos nunca tiveram contato.

Aluno2. As práticas experimentais é muito importante para a compreensão dos conteúdos

Aluno3. A experimentação pode ter um caráter indutivo e nesse caso, o aluno pode controlar variáveis e descobrir ou redescobrir relações funcionais entre elas, e pode também ter um caráter dedutivo quando eles têm a oportunidade de testar o que é dito na teoria.

\section{Aluno4. Muito boas}

Aluno5. Bom, primeiramente eu gostaria de esclarecer que nas respostas abaixo de sim ou não, eu só tenho aulas experimentais pq o professor se desdobra para tentar nos proporcionar as aulas experimentais.. E sim, na minha escola tem laboratório, mas é cheio de caixas e quase não se é utilizado...

Agr sim irei responder a pergunta feita aqui...

A importância das práticas experimentais para mim pelo menos, é que com elas posso ter a experiência de como tudo é feito, e assim aprendemos mais. É como um velho ditado "Com a prática vem a perfeição."

Aluno6. Sim e muito

Aluno7. É importante que o aluno pratique o experimento químico,para que descubra e veja o que é dito na aula teórica,assim fazendo com que ele teste novos conceitos da química e aprenda melhor na prática.

Aluno8. Através de experiências fica mais fácil de entender o assunto abordado.

Aluno9. Muito grande já que assim se vê na prática e não apenas na tese presentada nós livro Aluno10. O trabalho experimental deve estimular o nosso desenvolvimento, fazendo com que a gente explore e elabore as nossas ideias

E os outros responderam só com pontos.

\section{RESPOSTA2.}


Você tem dificuldade para aprender química?

12 respostas

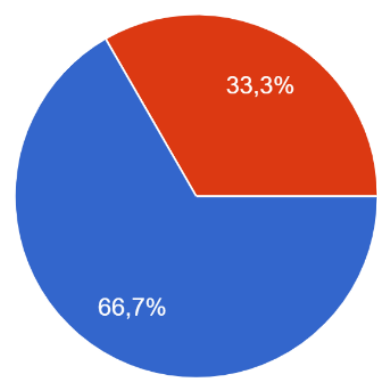

\section{RESPOSTA3.}

Você tem aulas experimentais na aula de Química?

12 respostas

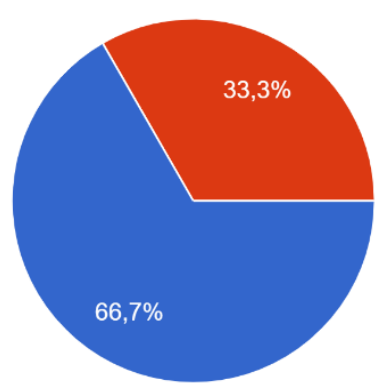

\section{RESPOSTA4.}

Sua escola tem laboratório de química?

12 respostas

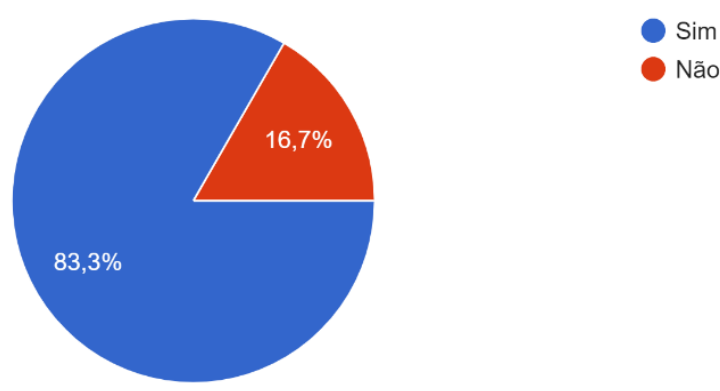




\section{RESPOSTA5.}

Você gosta da matéria de Química?

12 respostas

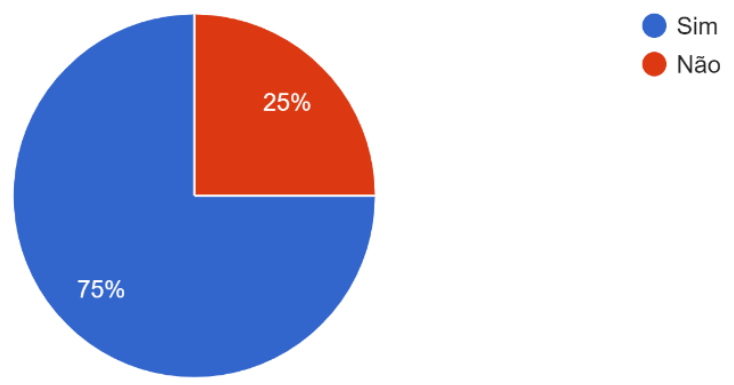

Respostas dos alunos da escola Cônego Fernando Passos.

\section{RESPOSTA1.}

Aluno1. Para ver fenômenos q ocorrem durante a experiência, gerar discussões, tirar eventuais dúvidas e mostrar na prática como realizar experiências

Aluno2. Para mim eu acho muito importante

Aluno3. Para entendermos como podemos usar elementos da quimica

Aluno4. Poder ter o contato com o conteúdo de forma divertida, saindo do ambiente chato de sala de aula dá mais vontade de aprender

Aluno5. Para desenvolver a capacidade de compreender os fenômenos químicos no dia a dia Aluno6. É muito importante que o professor use métodos diferentes como as atividades experimentais para melhor compreensão.

Aluno7. É muito importante que o professor use metos diferentes pra auxiliar na compreensão de conteúdos da química.

Aluno8. É importante pois o presente estudo tem por objetivo analisar a importancia das atividades experimentais como estratégias dinâmicas essências para a melhoria do ensino de química

Aluno9. Para aprender mais a química

Aluno10. É importante pois o presente estudo tem por objetivo analisar a importância das atividades experimentais como estratégias dinâmica essências para a melhoria do ensino de 
Química.

Aluno11. É importante pois o presente estudo tem por objetivo analisar a importância das atividades experimentais como estratégias dinâmicas essências para a melhoria do ensino de quimica.

Aluno12. É muito importante pois facilita no nosso aprendizado.

Aluno13. Os experimentos nos ajudam a ter compreensão mais científica das transformações que ocorrem na natureza.

\section{Resposta2.}

Você tem dificuldade para aprender química?

20 respostas

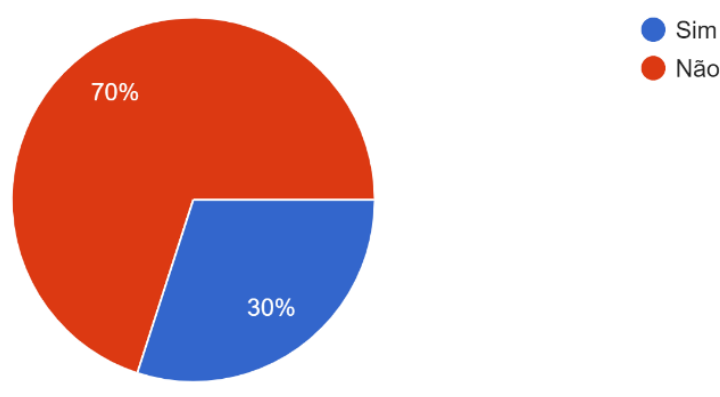

\section{Resposta3.}

Você tem aulas experimentais na aula de Química?

20 respostas

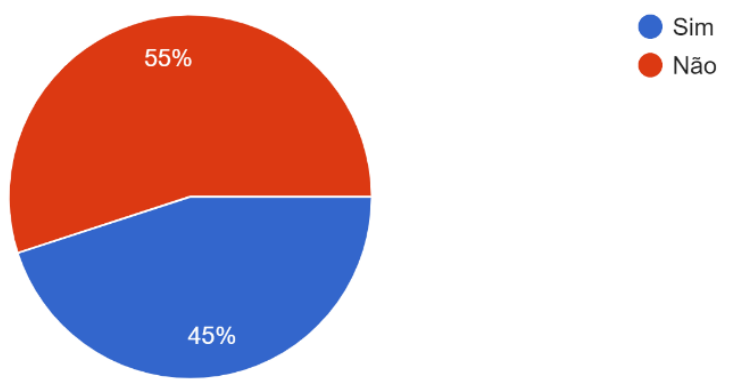

\section{Resposta4.}




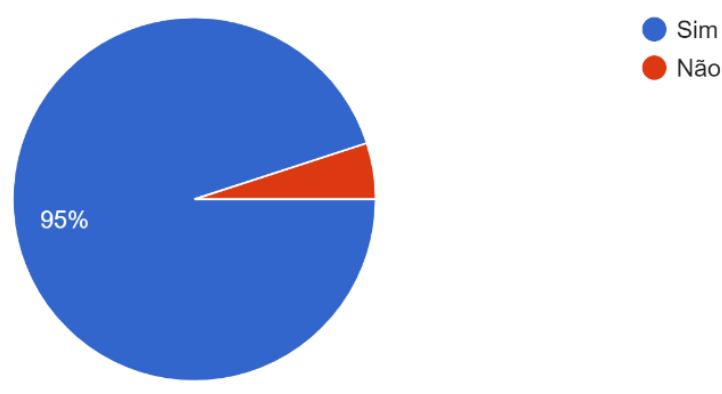

\section{Resposta5.}

Você gosta da matéria de Química?

19 respostas

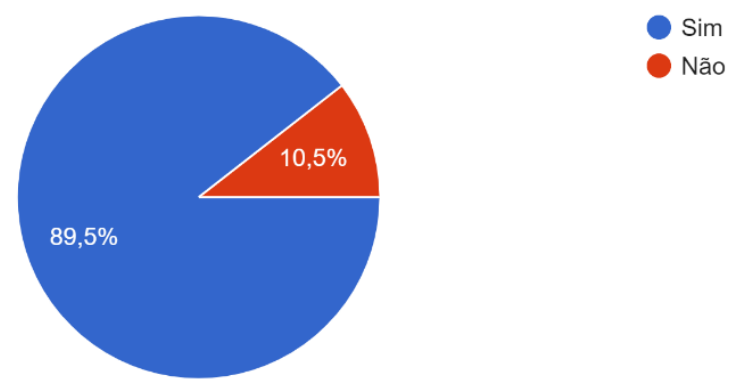

Obervamos que os alunos sabem a importância das práticas experimentais no ensino da química, para que eles venham aprender mais sobre o conteúdo, e cerca de $31,65 \%$ dos alunos que tem dificulade de aprender os conteúdos da química, e as práticas experimentais é um meio facilitador para com que os alunos venham aprender e ter mais curiosidade sobre a química de uma maneira mais dinâmica e esses meios que fazem os alunos sentirem mais curiosidade sobre os conteúdos.

\section{CONCLUSÕES}

As contribuições das atividades experimentais no ensino de Química é um tema propício e relevante para o desenvolvimento da ciência na educação, e essa pesquisa retratou as principais práticas experimentais. Foi possível observar as diversas possibilidades que o professor tem de realizar essas atividades em sala de aula.

Em nossa pesquisa, foi possível observar que os professores de escolas de rede públicas, têm muitas dificuldades em trabalhar as práticas experimentais em sala de aula, nem tanto por 
conta dos materiais pois eles buscam materiais alternativos, mais sim por conta do espaço e do tempo que é muito curto, mas eles sempre buscam meios diferentes para levar os conteúdos de química para a sala de aula.

Observamos também que os estudantes sabem o quanto essa prática é importante para o seu aprendizado e como as práticas experimentais auxiliam eles em relação aos conteúdos, trabalhado em sala, o uso da experimentação torna as aulas mais atrativas.

Verificamos também o quanto o ensino de Química precisa ser renovado, afinal, esses estudos trazem perspectivas que não são corriqueiras nas salas de aula. Muitos professores permanecem com práticas experimentais relacionadas às abordagens tradicionais.

Ressaltamos a importâncias dessas propostas serem discutidas nos cursos de formação de professores para que o ensino, no nosso caso, da Química supere as práticas tradicionais (MIZUKAMI, 1986) que, historicamente (VIANA, 2014), são realizadas.

\section{REFERÊNCIAS}

ALVES FILHO, J. P. Atividades Experimentais: do método à prática construtivista. 448f. Santa Catarina, 2000. Tese (Educação), Centro de Ciências da Educação, Universidade Federal de Santa Catarina - UFSC, Florianópolis, 2000.

AMARAL, L. Trabalhos práticos de química. São Paulo, 1996

BRASIL, BASES LEGAIS - Parâmetros Curriculares Nacionais; MÉDIO, Parâmetros Curriculares Nacionais Ensino. PCN+ para o Ensino de Ciências e Matemática. Brasília: Ministério da Educação, 2002.

BRASIL. Ministério da Educação. Orientações curriculares para o ensino médio: ciências da natureza, matemática e suas tecnologias. Brasília, 2006.

BRASIL. Ministério da Educação. Secretaria de Educação Média e Tecnológica. Diretrizes Curriculares Nacionais Gerais da Educação Básica. Diretoria de Currículos e Educação Integral. Brasília, 2013. 562p.

CARVAlHO, A. M. P. Ensino de Ciências por Investigação: condições para implementação em sala de aula. São Paulo: Cengage Learning, 2013.

LIMA, K. S. Compreendendo as concepções de avaliação de professores de física através da teoria dos construtos pessoais. Recife, 2008. 163 p. Dissertação (Mestrado em Ensino das Ciências). Pró-Reitoria de Pesquisa e Pós-Graduação, Universidade Federal Rural de Pernambuco, 2008.

MIZUKAMI, MGN. Ensino: as abordagens do processo. São Paulo: EPU, 1986.

SAVIANI, O. Pedagógia histórico-crítica: primeiras aproximações. 7. ed. Campinas, SP: Autores Associados, 2000.

VIANA, K. S. L. Avaliação da Experiência: uma perspectiva de Avaliação para o ensino 
das Ciências da Natureza. 202f. Recife, 2014. Tese (Ensino de Ciências e Matemática). Departamento de Educação, Universidade Federal Rural de Pernambuco - UFRPE, Recife, 2014. 